\title{
RETIREE HEALTH INSURANCE AND \\ THE LABOR FORCE BEHAVIOR \\ OF OLDER MEN IN THE 1990S
}

\author{
David M. Blau \\ Donna B. Gilleskie
}

Working Paper 5948

\section{NATIONAL BUREAU OF ECONOMIC RESEARCH 1050 Massachusetts Avenue \\ Cambridge, MA 02138 \\ February 1997}

Financial support from the National Institute on Aging is gratefully acknowledged. Comments on a previous draft presented at the 1997 Winter meeting of the Econometric Society in New Orleans and in seminars at UNC - Chapel Hill, Syracuse, Penn State, Stanford, and the NBER were helpful. This paper is part of NBER's research program in Health Care. Any opinions expressed are those of the authors and not those of the National Bureau of Economic Research.

(C) 1997 by David M. Blau and Donna B. Gilleskie. All rights reserved. Short sections of text, not to exceed two paragraphs, may be quoted without explicit permission provided that full credit, including $(\mathcal{C}$ notice, is given to the source. 
Retiree Health Insurance and the Labor Force

Behavior of Older Men in the 1990s

David M. Blau and Donna B. Gilleskie

NBER Working Paper No. 5948

February 1997

JEL Nos. J26, I1

Health Care

\section{ABSTRACT}

We estimate the impact of employer-provided retiree health insurance on the rate at which men aged 51-62 enter and exit the labor force and switch jobs. The models estimated are an approximation of the employment decision rules implied by a dynamic stochastic model of employment behavior of older individuals. We use data from the Health and Retirement Survey (HRS), which contains more detailed and accurate measures of retiree health insurance than those used in most previous studies. The results show that availability of employer-provided retiree health insurance (EPRHI) increases the rate of exit from employment by two percentage points per year on average if the individual shares the cost of the insurance coverage with the firm, and by six percentage points if the firm pays the entire cost. The impact of EPRHI on the annual rate of labor force exit increases with age, reaching nine percentage points by age 61 . These are larger than the effects estimated in previous studies. The accurate and detailed health insurance measures available in the HRS help account for the larger effects found here. Controlling for unobserved heterogeneity, a possibility not accounted for in previous studies, also has a substantial impact on the estimates.

David M. Blau

Department of Economics

University of North Carolina

at Chapel Hill

Chapel Hill, NC 25799-3305

and NBER

dblau.econ@mhs.unc.edu
Donna B. Gilleskie

Department of Economics

University of North Carolina at Chapel Hill

Chapel Hill, NC 25799-3305

and NBER

donna_gilleskie@unc.edu 


\section{Introduction}

The effect of health insurance reform on the employment behavior of older workers is of considerable interest. A reform that breaks the close link between employment and health insurance coverage could lead to a substantial increase in the already high rate of labor force exit before age 65 . Two observations suggest that retiree health insurance may play an important role in retirement decisions of older workers. The labor force participation rate (LFPR) of men aged 55-64 declined sharply in the 1970's but much more slowly in the 1980's. Social Security retirement benefits have been suggested as an explanation because benefits became considerably more generous during the 1970 's, but did not increase by much in real terms in the 1980's. However, eligibility for Social Security benefits does not begin until age 62, but the decline in the male LFPR was quite large at ages 59-61 as well as 62-64 (Burkhauser and Quinn, 1994; Peracchi and Welch, 1994). Furthermore, studies based on time-series data find that increased generosity and coverage of Social Security can account for only a small part of the decline in the male LFPR. ${ }^{1}$ Time series data on retiree health insurance are not available, but cross-section data from a variety of sources suggest that such coverage became increasingly common in the 1970's and then declined from the mid 1980's through the 1990's. ${ }^{2}$ This suggests the possibility that changes in the prevalence of retiree health insurance may have contributed to changing patterns of retirement.

A second observation that suggests the potential importance of retiree health insurance in retirement decisions is the sharp spike in the labor force exit rate at age $65 .{ }^{3}$ Workers who place a high value on health insurance and whose employers do not provide retiree health insurance may choose to delay retirement until they become eligible for Medicare benefits at age 65, particularly in view of the high cost of privately purchased health insurance. Many other explanations for the age-65 spike in the labor force exit rate have been proposed, but

\footnotetext{
${ }^{1}$ See Moffitt (1987), Krueger and Pischke (1992), and Stewart (1994) for evidence. Hurd (1990) summarizes the large literature on the effects of Social Security and pensions on retirement timing.

${ }^{2}$ See Madrian (1994), Fronstin et al. (1994), Jensen and Morrisey (1992), Wilcox-Gok and Rubin (1994), Shea and Stewart (1994), Morrisey (1993), Morrisey, Jensen, and Henderlite (1990), and Loprest and Zedlewski (1995).

${ }^{3}$ There is also a sharp spike at age 62 . Liquidity constraints caused by the prohibition against using future benefits as collateral for consumption loans have been proposed as an explanation for the "excess" labor force exit rate at age 62. See Kahn (1988) and Burtless and Moffitt (1985) for evidence on this.
} 
most have received little empirical support (Lumsdaine, Stock, and Wise, 1996). The absence of employer-provided retiree health insurance coverage for many workers and the availability of Medicare coverage at age 65 is one plausible explanation for the age-65 spike that has received some support. ${ }^{4}$

Reduced form evidence from previous studies suggests that workers with employerprovided retiree health insurance (EPRHI) tend to leave the labor force at younger ages than otherwise similar workers without such coverage. Gruber and Madrian $(1995,1996)$ exploit the "natural experiment" generated by passage of Continuation Coverage mandates by a number of states, and followed by Federal passage as part of the 1985 Consolidated Omnibus Budget Reconciliation Act (COBRA). These mandates require firms with employment above some minimum level to provide continuation of health care benefits for up to 18 months to workers who leave the firm. Gruber and Madrian show that men aged 62-64 were 3 to 5 percent more likely to be out of the labor force in those years and states in which a mandate was in effect. Madrian's (1994) estimates based on cross-section samples of workers already retired at the survey date suggests that individuals with EPRHI coverage retired up to 1.5 years earlier than otherwise similar individuals without such coverage. ${ }^{5}$

Three recent studies have estimated structural models of labor force exit decisions that incorporate health insurance. Gustman and Steinmeier (1994) and Lumsdaine, Stock, and Wise (1994) use models they had previously developed for the purpose of estimating the impact of Social Security and pensions on labor force exit behavior. They add to the budget constraint measures of the average cost of health insurance, reestimate their models, and find that the parameter estimates and implied retirement behavior are virtually identical with or without health insurance included. Rust and Phelan (forthcoming) argue convincingly that this approach is likely to be a serious misspecification. The expected value of medical expenses is relatively low at ages 55-64, so valuing health insurance coverage at its average cost changes the budget constraint by only a small amount. But a major component of the

\footnotetext{
${ }^{4}$ Each year that an individual works past age 65 provides a smaller increase in Social Security benefits than does an additional year worked from age 62 to age 65 . However, this difference in the rate at which continued work is rewarded by the Social Security system is too small to account for the sharp age- 65 spike in the labor force exit rate (Blau, 1994). Most defined benefit pension plans encourage early retirement, typically well before age 65. (Lumsdaine, Stock, and Wise, 1994). Whether Medicare can account for the age-65 spike in the labor force exit rate is unsettled: see Lumsdaine, Stock, and Wise (1996) for a recent discussion.

${ }^{5}$ See also Karoly and Rogowski (1994).
} 
value of health insurance to risk-averse individuals is the coverage it provides against lowprobability catastrophic health events. The estimates of these two studies cannot account for this source of demand for insurance. Rust and Phelan allow for risk aversion and model the entire distribution of medical expenditures rather than the mean only. Their estimates indicate that individuals in their Retirement History Survey (RHS) sample are quite risk averse and that the availability of EPRHI has a substantial impact on the timing of labor force exit. Their data show that men aged 60-61 with EPRHI coverage are up to 10 percentage points more likely to exit the labor force during a two year period than men without EPRHI, and their model reproduces this feature of the data quite closely.

There are several problems with previous studies that make a new analysis worthwhile. First, most of the existing studies have not had access to accurate information about the retiree provisions of health insurance plans. For example, Gustman and Steinmeier (1994) and Karoly and Rogowski (1994) had no information on EPRHI and imputed EPRHI coverage from other data sources based on industry, firm size, and region. Rust and Phelan had no direct information on EPRHI coverage and imputed coverage by observing how health insurance coverage of the men in their sample changed over time as their employment status changed. Madrian (1994) used three data sets, only one of which contains specific information on EPRHI; EPRHI coverage is inferred from other questions about health insurance in the other data sources. In each of these studies EPRHI coverage was likely measured with error, introducing biases into their estimates of the effects of EPRHI coverage. Secondly, much of the data used in previous studies is either cross-sectional, longitudinal but old, or derived from a single firm. Lumsdaine, Stock, and Wise (1994) use longitudinal data from a single firm. Gustman and Steinmeier (1994) and Rust and Phelan use longitudinal data from the RHS, which ended in 1979 and may be quite dated for purposes of analyzing current trends and policies. Madrian (1994) and Gruber and Madrian $(1995,1996)$ use both cross-sectional data and short panels from the Survey of Income and Program Participation (SIPP). ${ }^{6}$ Karoly and Rogowski (1994) also use short panels from the SIPP. We show below that cross-sectional data are likely to be of limited use in analyzing the effect of EPRHI on labor force behavior because

\footnotetext{
${ }^{6}$ Madrian (1994) treats the SIPP data as cross-sections due to limited ability to measure the EPRHI coverage of workers who had not retired as of the survey date.
} 
of unobserved heterogeneity that induces spurious correlation between EPRHI and labor force status. This problem can be overcome by using longitudinal data. The SIPP data are useful and relatively recent, but all of the studies that use these data treat initial employment status as given. These studies are thus potentially subject to the same unobserved heterogeneity problem as studies using cross-sectional data. Finally, all of the studies cited above treat health insurance and EPRHI coverage as exogenous. Health insurance and EPRHI could be endogenous for a number of reasons: both are job characteristics, and individuals choose a job; some employers offer multiple health insurance plans, and workers choose a plan; and some workers have access to a health insurance plan from the spouse's employer, and choose whether to be covered by their own employer's plan, the spouse's employer's plan, both, or neither. Cameron et al. (1988) test and reject the hypothesis that health insurance coverage is exogenous in a model of medical care demand.

In this paper we estimate the impact of retiree health insurance on the rate of labor force entry and exit and job switching of older men using data from the Health and Retirement Survey (HRS). The equations we estimate represent an approximation of the employment decision rules implied by a dynamic stochastic model of employment decisions. These equations include measures of retiree health insurance coverage that are similar to those used in previous studies, but that are more accurately measured and provide greater detail on the provisions of coverage. For example, the HRS provides information on whether the respondent pays the entire cost of EPRHI coverage, a potentially important determinant of the effect of EPRHI. Our specification also includes measures of a number of other important job characteristics that may influence employment behavior and are likely to be correlated with the availability of EPRHI, including detailed measures of pension characteristics. We use a flexible semi-parametric random effects specification to account for the possibility of unobserved heterogeneity. As part of this specification, models for initial employment status, health status, health insurance coverage, and EPRHI coverage are estimated jointly with the employment transition models. Our results provide clear evidence that these initial conditions are endogenous. The empirical results indicate that EPRHI coverage has a strong positive effect on exit from employment and a sizable negative impact on entry to employment. These effects are especially large for men aged 59 to 61 . The estimated effects of EPRHI coverage 
in our results are larger than those found in previous studies. We demonstrate that this is due in part to controlling for unobserved heterogeneity, and also to the availability of more accurate measures of health insurance in the HRS than those used in most previous studies. Section 2 describes the behavioral model and the employment equations derived from the model. Section 3 discusses the HRS data, section 4 presents and discusses the estimates, and section 5 concludes.

\section{The Model}

We expect that older men with employer-provided health insurance that also provides EPRHI coverage are more likely to exit the labor force and are less likcly to change jobs or reenter the labor force than are otherwise similar men without EPRHI coverage. EPRHI provides insurance against unforeseen medical expenses while not employed. A risk-averse man who is subject to a non-negligible risk of an adverse health outcome that would require large medical expenditures is less likely to leave his job until becoming eligible for Medicare if leaving his job means giving up his employer-provided coverage. Furthermore, a man's current health status provides information about the distribution of future health outcomes, so we expect that EPRHI coverage will have a stronger effect on behavior for men in worse health. That is, the perceived probability of an adverse health outcome will influence the strength of the EPRHI effect on employment transitions. The effect of EPRHI on employment transitions might also depend on age, but the direction of the age effect is not obvious a priori. An older man without EPRHI faces a shorter period without insurance if he leaves his job than a younger man, since Medicare eligibility begins at 65 . This suggests that the effect of EPRHI would diminish with age. But for a given current health status the perceived risk of a poor

health outcome in the future is likely to increase with age, causing the effect of EPRHI on employment transitions to become stronger with age.

We develop a simple model that incorporates these ideas and use it to demonstrate the conditions under which these propositions hold. We then develop an econometric model that represents an approximation to the decision rules implied by the theory. 
The structure of the model is as follows. ${ }^{7}$ Time is discrete and there is a finite horizon, $T$. An individual chooses his employment status at the beginning of each period. Employment status remains fixed for the duration of the period once it has been chosen. We assume that the individual's health status for the period becomes known to him only after he has chosen his employment status for the period. This assumption simplifies the analysis but does not affect the main results. There are two possible employment states at period $t-1$ : employed and not employed. Hours worked are fixed when employed. If an individual was employed in period $t-1$, his alternatives in period $t$ are to (1) become non-employed, (2) take a new job, or (3) remain in the current job. If he was not employed in the previous period, he faces only the first two alternatives: remain non-employed or accept a new job. One new job offer is received at the beginning of each period with no cost of search. The characteristics of the new job offer, including the wage rate and health insurance coverage provisions, are denoted by the vector $\mathbf{N}_{t}$. The employment alternatives are denoted by $j$ with a maximum of $J=3$ alternatives (nonemployment, new job, or same job). The state variables determined by the choices made in previous periods are denoted by a vector $\mathbf{s}_{t}$ and include the employment state at the end of the previous period, cumulative years of job tenure, and characteristics of the current job (or last job, if not currently employed). The current employment decision has future consequences because earnings and nonwage income depend on job tenure and because health insurance is a job characteristic. We assume that there is no capital market.

There are two health states: good $\left(h_{t}=0\right)$ and bad $\left(h_{t}=1\right)$. Transitions among health states are exogenous and are determined by a Markov process. The individual's health status for the period becomes known to him following his employment decision for that period. Conditional on surviving to period $t$, the probability of making a transition from health state $i$ in period $t-1$ to health state $a$ in period $t$ is given by

$$
\pi_{t}^{i a}\left(\mathbf{Z}_{t}, \mu\right)=\mathrm{p}\left(h_{t}=a \mid h_{t-1}=i, \mathbf{Z}_{t}, \mu\right)
$$

where $\pi_{t}^{i 0}+\pi_{t}^{i 1}=1 \forall i, \forall t, \mathbf{Z}_{t}$ is a vector of observed exogenous characteristics, and $\mu$ is an unobserved permanent heterogeneity component. The probability of dying in the period prior

\footnotetext{
${ }^{7}$ See Rust and Phelan (forthcoming) for a related model.
} 
to $t$ (i.e., not surviving to period $t$ ) depends on the individual's health status in period $t-1$ and unobserved heterogeneity; it is denoted $\delta_{t}^{i}$.

Utility during period $t$ is given by

$$
U^{i}\left(C_{t}, \mathbf{d}_{t}, \mathbf{Z}_{t}, \mu, \epsilon_{t}^{i}\right)=\bar{U}^{i j}\left(C_{t}, \mathbf{Z}_{t}\right)+\rho_{i j} \mu+\epsilon_{t}^{i j}
$$

where $C_{t}$ is consumption of a composite commodity, $\mathbf{d}_{t}=\left(d_{t}^{j}, \forall j\right)$ is a vector indicating which employment alternative is chosen, $\epsilon_{t}^{i}=\left(\epsilon_{t}^{i j}, \forall i, j\right)$ is a vector of period $t$ state-specific utility shocks known to the individual at the beginning of period $t, \bar{U}^{i j}(\cdot)$ is the utility of consumption, and $\rho_{i j}$ is a parameter. The utility derived from consumption is allowed to depend on current health and employment status. If $\bar{U}^{i j}(\cdot)$ is concave, then individuals are risk-averse and will be willing to purchase actuarially fair health insurance.

The budget constraint is given by

$$
C_{t}=e_{t}\left(1-d_{t}^{1}\right)+b_{t}-m_{t} \quad \forall t
$$

where $e_{t}$ is earnings in period $t, d_{t}^{1}=1$ if the individual chooses the nonemployment state in period $t$ and equals zero otherwise, $b_{t}$ is nonwage income (benefits) in period $t$, and $m_{t}$ represents the individual's out-of-pocket medical expenditures during period $t$. Earnings are given by $e_{t}=e\left(t, \mathbf{d}_{t}, \mathbf{s}_{t}\right)$ and are, thus, a function of tenure in the current employment state (an element of the vector of state variables $\mathbf{s}_{t}$ ). Nonwage income is defined by $b_{t}=b\left(t, \mathbf{d}_{t}, \mathbf{s}_{t}\right)$. This specification of the nonwage income function is flexible enough to incorporate Social Security and pension benefits as a function of employment status, tenure, and age. Out-ofpocket medical expenses, $m_{t}$, depend on the amount of medical care services purchased, the market prices of the services purchased, and the characteristics of health insurance coverage. To keep the model simple, we do not treat medical care consumption as a choice variable, but rather assume that it is determined by current health status. ${ }^{8}$ Thus, the function determining out of pocket medical expenses can be written as $m_{t}=m\left(t, h_{t}, \mathbf{d}_{t}, \mathbf{s}_{t}\right)$. The characteristics of health insurance such as the premium, deductible, and coinsurance rate are elements of the state vector $\mathbf{s}_{t}$, and may depend on employment status. This is a central feature of the

\footnotetext{
${ }^{8}$ This is similar to the specification of medical expenses in Rust and Phelan. Elsewhere, we develop a more elaborate model in which medical care is a decision variable and affects health and utility directly (Blau and Gilleskie, 1996). See also Gilleskie (1997).
} 
model: some individuals have EPRHI coverage that makes some or all of these characteristics independent of employment status, while other individuals may lose coverage or have coverage with different characteristics if they leave their current employer. Market prices for medical visits are also elements of $\mathbf{s}_{t}$ but do not depend on employment status.

The Expected Present Discounted Value (EPDV) of lifetime utility from choosing employment state $j$ in period $t<T$, given health status $i$ in the previous period and the characteristics $\mathbf{N}_{t}$ of the new job offer, ${ }^{9}$ is

$$
\begin{aligned}
V_{j}^{i}\left(\mathbf{s}_{t}, \epsilon_{t}^{i} \mid \mathbf{N}_{t}\right)= & \pi_{t}^{i 0}\left[U^{0}\left(C_{t}, \mathbf{d}_{t}, \mathbf{Z}_{t}, \mu, \epsilon_{t}^{0}\right)+\beta\left(1-\delta_{t+1}^{0}\right) V^{0}\left(\mathbf{s}_{t+1}\right)\right] \\
+ & \pi_{t}^{i 1}\left[U^{1}\left(C_{t}, \mathbf{d}_{t}, \mathbf{Z}_{t}, \mu, \epsilon_{t}^{1}\right)+\beta\left(1-\delta_{t+1}^{1}\right) V^{1}\left(\mathbf{s}_{t+1}\right)\right] i=0,1, \forall t
\end{aligned}
$$

where $\beta$ is the discount factor, the value of utility at death is zero, and $V^{i}\left(\mathbf{s}_{t}\right)$ is the maximal expected value of utility in a particular health state $i$ (i.e., $V^{i}\left(\mathbf{s}_{t}\right)=\mathrm{E}_{t}\left[\max \left[V_{j}^{i}\left(\mathbf{s}_{t}, \epsilon_{t}^{i}\right), \forall j\right]\right], \forall t$ ) .

To illustrate the implications of the model, consider the following very simple special case. Suppose that the only state variable is EPRHI status: the state vector $\mathrm{s}_{t}$ consists of the single variable $s_{t}=1$ if the individual has EPRHI coverage and zero otherwise. Assume that all jobs provide health insurance and the same level of earnings, so that jobs differ only in whether they offer EPRHI. Health insurance carries a constant premium $p$ regardless of whether it offers EPRHI, and, if the job offers EPRHI, then the premium $p$ is also paid when not employed. If health is good, then medical expenses are zero. If health is bad, then medical expenses of $m$ are incurred. These expenses are fully covered by health insurance or EPRHI but are paid by the individual if he is not employed and not covered by EPRHI. Benefits $(b)$ are zero if employed and are constant and independent of the date of labor force exit if not employed. Finally, let the utility of consumption be $C^{\alpha_{j}}$, where $0 \leq \alpha_{j} \leq 1$.

Consider a man who was employed in period $T-1$, enters period $T$ in health state $i$, and is deciding whether to exit the labor force (alternative 1), take a new job (alternative 2), or remain on the current job (alternative 3 ) during period $T$. Because there are no future effects

\footnotetext{
${ }^{9} \mathrm{As}$ indicated above, we assume that an individual receives one new job offer per period, but we do not observe the characteristics $N_{t}$ of the job offer unless the individual accepts the new job. The probability that the offer received is from one of the $F$ types of jobs available is $\lambda_{f}, f=1, \ldots, F$. Thus, unconditional on the characteristics of the new job, the EPDV of lifetime utility is $V_{j}^{i}\left(\mathbf{s}_{t}, \epsilon_{t}^{i}\right)=\sum_{f=0}^{F} \lambda_{f} V_{j}^{i}\left(\mathbf{s}_{t}, \epsilon_{t}^{i} \mid \mathbf{N}_{t}^{f}\right)$.
} 
of decisions made in period $T$, because jobs differ by EPRHI availability only, and because all jobs are assumed to provide health insurance to active workers, characteristics of the new job offer are irrelevant to the period $T$ decision. We ignore $\mu$ and $\epsilon$ since they have no bearing on the predictions (i.e., $\left.\bar{V}_{j}^{i}\left(s_{t} \mid \cdot\right)=V_{j}^{i}\left(s_{t}, \epsilon_{t}^{i} \mid \cdot\right)-\rho_{i j} \mu-\epsilon_{t}^{i j}\right)$. If the current job has EPRHI coverage (i.e., $s_{T}=1$ ), then the value associated with each alternative is

$$
\begin{aligned}
& \bar{V}_{1}^{i}\left(s_{T}=1 \mid \cdot\right)=(b-p)^{\alpha_{1}} \\
& \bar{V}_{2}^{i}\left(s_{T}=1 \mid \cdot\right)=(e-p)^{\alpha_{2}} \\
& \bar{V}_{3}^{i}\left(s_{T}=1 \mid \cdot\right)=(e-p)^{\alpha_{3}}
\end{aligned}
$$

The value of each alternative if the current job does not provide EPRHI (i.e., $s_{T}=0$ ) is

$$
\begin{aligned}
& \bar{V}_{1}^{i}\left(s_{T}=0 \mid \cdot\right)=\pi^{i 0} b^{\alpha_{1}}+\left(1-\pi^{i 0}\right)(b-m)^{\alpha_{1}} \\
& \bar{V}_{2}^{i}\left(s_{T}=0 \mid \cdot\right)=(e-p)^{\alpha_{2}} \\
& \bar{V}_{3}^{i}\left(s_{T}=0 \mid \cdot\right)=(e-p)^{\alpha_{3}}
\end{aligned}
$$

The optimal choice will be to exit the labor force if $\bar{V}_{1}(\cdot)-\bar{V}_{2}(\cdot)>0$ and $\bar{V}_{1}(\cdot)-\bar{V}_{3}(\cdot)>$ 0. EPRHI does not affect the value of employment, as the above expressions show, since all jobs are assumed to provide health insurance to active employees. Therefore, EPRHI unambiguously increases the likelihood of exiting the labor force in period $T$ if $\bar{V}_{1}^{i}\left(s_{T}=1\right.$ | $\cdot)-\bar{V}_{1}^{i}\left(s_{T}=0 \mid \cdot\right)>0$. Substituting from above,

$$
\bar{V}_{1}^{i}\left(s_{T}=1 \mid \cdot\right)-\bar{V}_{1}^{i}\left(s_{T}=0 \mid \cdot\right)=(b-p)^{\alpha_{1}}-\left[\pi^{i 0} b^{\alpha_{1}}+\left(1-\pi^{i 0}\right)(b-m)^{\alpha_{1}}\right]
$$

The expression in equation 5 is positive if the premium is zero and in general will be positive if utility with insurance exceeds the expected value of utility without insurance. Therefore, in this simple example EPRHI increases the likelihood of exit from the labor force in period $T$. Furthermore, the expression is clearly decreasing in $\pi^{i 0}$, so the higher the chance of experiencing bad health (i.e., the smaller the value of $\pi^{i 0}$ ) the larger is the effect of EPRHI on labor force exit. It is straightforward to show that the likelihood of changing jobs and the likelihood of entering employment conditional on being out of the labor force are both determined by the same expression with the sign reversed. So EPRHI decreases labor force entry and job switching. The intuition for these results is clear: EPRHI raises current utility 
when not employed, but does not affect current utility when employed. Additionally, it can be shown that EPRHI increases the value of future utility unconditional on the employment state or the job offer characteristics, so the sign of equation 5 also determines the effect of EPRHI in all periods. Although these results could be much more difficult to demonstrate in a more complex model, EPRHI will tend to increase the relative attractiveness of labor force exit in any model with health risk.

In this paper we do not attempt to estimate the structural parameters by solving the dynamic programming problem. It will be feasible to estimate these parameters of the behavioral model when the HRS releases all of the necessary data on pension and health plan characteristics, so we leave this for a future paper. Here, we propose to estimate a model that represents an approximation to the employment decision rules derived from the behavioral model.

We specify a linear approximation to the value of occupying employment state $j$ in period $t$, conditional on having been in employment state $k$ in period $t-1$, as

$$
V_{k j t}=\mathbf{X}_{t-1} \gamma_{k j}+\rho_{k j} \mu+\epsilon_{k j t}
$$

where $\mathrm{X}$ is a vector of state variables, including job tenure, the wage rate, and characteristics of the individual's health insurance and pension coverage. These variables have direct effects on the current period decision but also may affect current behavior because they determine expectations of future values of random variables. The approximation approach does not attempt to disentangle the effects of variables in $\mathbf{X}_{t-1}$ on current and future decisions, in contrast to the structural estimation approach.

The probability of making a transition from employment state $k$ to $j$ is given by

$$
\mathrm{P}\left(V_{k j t}>V_{k j^{\prime} t}, \forall j^{\prime} \neq j\right)=\frac{\exp \left(\mathbf{X}_{t-1} \gamma_{k j}+\rho_{k j} \mu\right)}{\sum_{j^{\prime}=1}^{J_{k}} \exp \left(\mathbf{X}_{t-1} \gamma_{k j^{\prime}}+\rho_{k j^{\prime}} \mu\right)}
$$

where $J_{k}$ is the number of employment alternatives available to an individual in state $k$, and the $\epsilon$ 's are assumed to be independently Extreme Value distributed. These assumptions yield a set of dynamic multinomial logit models of transitions among employment states. The models are dynamic because of the (testable) assumption that the probability of occupying state $j$ today depends on the state occupied in the previous period, and because $\mathbf{X}$ contains lagged 
endogenous variables. The models are linked by dependence on the common unobserved factor $\mu$, which is treated as a random effect and is integrated out of the model. We follow Mroz and Guilkey (1992) and Heckman and Singer (1984) in approximating the distribution of $\mu$ by a step function. The points of support of the distribution, the factor loadings $(\rho)$, and the probabilities associated with each point of support are estimated jointly with the other parameters.

An important consideration in obtaining consistent estimates of the parameters of this model is the fact that tenure, the wage rate, health insurance coverage, health status, and other state variables observed at the initial survey are likely to be correlated with the permanent error component, $\mu$, if previous employment decisions were determined by the same model as the employment decisions beginning at the initial survey. Failure to account for the initial conditions problem would lead to inconsistent parameter estimates. We deal with this by specifying models for the initial conditions as of the first survey, allowing them to be functions of $\mu$, and estimating the parameters of the initial conditions models jointly with the other parameters. This approach was followed by Blau (1994) and is consistent with the approaches suggested by Heckman (1981). In addition to the endogenous initial conditions described above, we also allow health insurance and health observed in periods after the first survey to be endogenous. This accounts for the possibility that the unobserved determinants of health insurance and health decisions are correlated with the unobserved determinants of employment behavior. Finally, we model attrition from the survey between the first two waves. The likelihood function is given in the appendix.

\section{The Health and Retirement Survey Data}

The empirical analysis uses data from the first two waves of the HRS which were fielded in 1992 and 1994. We use the public release version of the first wave and the Beta release of the second wave. The population sampled in the HRS consists of men and women aged 51-61 in 1992 and, if married, their spouses. ${ }^{10}$ The sample contains 4,552 male respondents

\footnotetext{
${ }^{10}$ Blacks, Hispanics, and residents of the state of Florida were oversampled.
} 
aged 51-61; the sample used here includes 4,080 age-eligible men with complete data on key variables. ${ }^{11}$ About nine percent of these men were not interviewed in the second wave.

Employment Status. Employment status can be measured in the HRS at monthly intervals between surveys. However, other key variables such as health and health insurance are measured only as of the survey dates. We analyze employment transitions between the wave 1 survey date (denoted W1) and a date one year after the wave 1 survey (denoted W1+1), and between $\mathrm{W} 1+1$ and the wave 2 survey date (W2), which is two years after the wave 1 survey on average. This provides two annual employment transitions to explain. ${ }^{12}$ The variables used to explain transitions between $\mathrm{W} 1$ and $\mathrm{W} 1+1$ are from the $\mathrm{W} 1$ survey, and the variables used to explain transitions between $\mathrm{W} 1+1$ and $\mathrm{W} 2$ are from the $\mathrm{W} 2$ survey. Use of the W2 variables to explain decisions made at $\mathrm{W} 1+1$ is based on the arbitrary assumption that if the value of an explanatory variable is different at $W 1$ and $W 2$, then it changed by $W 1+1$. For example, if an individual indicated that the characteristics of his health insurance or pension coverage changed between $\mathrm{W} 1$ and $\mathrm{W} 2$ and the individual was employed at the same firm at both dates, then we do not know when the change occurred and the assumption that the change occurred by $\mathrm{W} 1+1$ is arbitrary. We make this assumption instead of using $\mathrm{W} 1$ values of variables to explain both transitions because it gives us more variation in the explanatory variables. ${ }^{13}$

Table 1 describes the distribution of the sample by employment status at the three dates. The employment rate falls from 78.5 percent at $\mathrm{W} 1$ to 76.0 percent at $\mathrm{W} 1+1$, and to 71.9 percent at W2. Table 1 also shows that the proportion of men employed in long-tenure jobs (at least five years) declines from 58.9 percent at W1 to 48.8 percent at W2, while the proportion employed in short-tenure jobs rises by three and one half percentage points. The proportion employed full time (over 30 hours per week) falls by seven and one half percentage

\footnotetext{
${ }^{11}$ Of 4,552 men aged 51-61 in the sample, we lose 43 due to unknown employment status, 189 due to missing data on net worth, 184 due to missing data on the age of the respondent's parents or whether the parents are alive, and the remaining 56 cases due to missing data on a number of other variables.

${ }^{12}$ Very few employment transitions occur between the one year intervals. Only 6 individuals change jobs more than once from $\mathrm{W} 1$ to $\mathrm{W} 1+1$ and only one individual has more than one job transition between $\mathrm{W} 1+1$ and W2. There are 32-42 cases with missing data on the variables needed for this calculation.

${ }^{13}$ In some cases we know the actual date of change of the variable and therefore do not need to make this assumption. For example, we know the month in which job changes occurred, so we can use actual job tenure as of $\mathrm{W} 1+1$ to explain transitions between $\mathrm{W} 1+1$ and $\mathrm{W} 2$. In a few other cases, W2 values of an explanatory variable were not available in the Beta release (wages, income, and assets).
} 
points between W1 and W2, while the proportion employed part time rises by almost one point.

Table 1: Employment Distribution of Men in the HRS

\begin{tabular}{lrrrrrr}
\hline \hline & \multicolumn{2}{c}{ Wave 1 } & \multicolumn{2}{c}{ Wave 1 + 1 year } & \multicolumn{2}{c}{ Wave 2 } \\
& Number & Percent & Number & Percent & Number & Percent \\
\hline & & & & & & \\
Employed & 3201 & 78.5 & 2760 & 76.0 & 2590 & 71.9 \\
Tenure $\geq 5$ yrs & 2405 & 58.9 & 1962 & 54.0 & 1760 & 48.8 \\
Full Time & 2314 & 56.7 & 1890 & 52.0 & 1681 & 46.6 \\
Part Time & 91 & 2.2 & 72 & 2.0 & 79 & 2.2 \\
Tenure < 5 yrs & 796 & 19.5 & 798 & 22.0 & 830 & 23.0 \\
Full Time & 691 & 16.9 & 685 & 18.9 & 708 & 19.6 \\
Part Time & 105 & 2.6 & 113 & 3.1 & 122 & 3.4 \\
& & & & & & \\
Not Employed & 879 & 21.5 & 872 & 24.0 & 1014 & 28.1 \\
Total & & & & & & 3604 \\
\end{tabular}

Note: Full Time $\equiv$ hours per week $\geq 30$. Part Time $\equiv$ hours per week $>0,<30$.

Table 2 presents employment transition matrices for $\mathrm{W} 1$ to $\mathrm{W} 1+1$ and $\mathrm{W} 1+1$ to $\mathrm{W} 2$. Of the non-censored cases, almost 88 percent of those employed remain on the same job between adjacent periods, five percent take a new job, and 7-8 percent leave employment. Of those not employed at W1, 14 percent of the non-censored cases are employed at $W 1+1$, while only seven percent of those not employed at $\mathrm{W} 1+1$ have taken a job by $\mathrm{W} 2$. The rate of exit from employment to nonemployment between $\mathrm{W} 1+1$ and $\mathrm{W} 2$ is over twice as large for those who changed jobs between $\mathrm{W} 1$ and $\mathrm{W} 1+1$ compared to those on the same job at $\mathrm{W} 1+1$ and $\mathrm{W} 1$. This suggests that "bridge jobs" are still an important labor market phenomenon for older men (Ruhm, 1990).

Health Insurance. The HRS collected information on health insurance coverage directly from respondents and by telephone interview with the employer or former employer. Health insurance data from the employer interviews are not yet available. Without these data it is not 
Table 2: Employment Transitions of Men in the HRS

\begin{tabular}{|c|c|c|c|c|c|}
\hline \multirow[b]{3}{*}{ Wave 1} & \multicolumn{5}{|c|}{ Wave $1+1$ year } \\
\hline & Same Job & New Job & Not Empl & Censored & Total \\
\hline & & & & & \\
\hline \multicolumn{6}{|l|}{$\overline{\text { Employed }}$} \\
\hline Number & 2512 & 140 & 212 & 339 & 3201 \\
\hline$\%$ of Non-Censored & 87.7 & 4.9 & 7.4 & & 100 \\
\hline \multicolumn{6}{|l|}{ Not Employed } \\
\hline Number & & 108 & 660 & 111 & 879 \\
\hline \multirow[t]{3}{*}{$\%$ of Non-Censored } & & 14.1 & 85.9 & & 100 \\
\hline & \multicolumn{5}{|c|}{ Wave 2} \\
\hline & Same Job & New Job & Not Empl & Censored & Total \\
\hline \multicolumn{6}{|l|}{ Wave $1+1$ year } \\
\hline \multicolumn{6}{|l|}{$\overline{\text { Employed }}$} \\
\hline Number & 2386 & 138 & 207 & 29 & 2760 \\
\hline$\%$ of Non-Censored & 87.4 & 5.0 & 7.6 & & 100 \\
\hline \multicolumn{6}{|l|}{ Same Job as Wave 1} \\
\hline Number & 2199 & 112 & 172 & 29 & 2512 \\
\hline$\%$ of Non-Censored & 88.6 & 4.5 & 6.9 & & 100 \\
\hline \multicolumn{6}{|l|}{ Different Job } \\
\hline Number & 187 & 26 & 35 & 0 & 248 \\
\hline$\%$ of Non-Censored & 75.4 & 10.5 & 14.1 & & 100 \\
\hline \multicolumn{6}{|l|}{ Not Employed } \\
\hline Number & & 65 & 806 & 1 & 872 \\
\hline$\%$ of Non-Censored & & 7.5 & 92.5 & & 100 \\
\hline
\end{tabular}


possible to incorporate in the analysis the complete set of relevant health insurance characteristics such as the premium, deductible, and copayment that enter the medical expenditure function $m_{t}=m\left(t, h_{t}, \mathbf{d}_{t}, \mathbf{s}_{t}\right)$. Instead, we specify dichotomous indicators of health insurance coverage from each of the following sources: (1) a group plan provided by a current or former employer; (2) a group plan provided by the spouse's current or former employer; (3) Medicare, (4) Medicaid, (5) the Veterans Administration or coverage provided to civilian employees of the military (VA/CHAMPUS); and (6) a privately purchased plan. Many individuals have coverage from more than one source. Individuals with no health insurance represent the omitted category in the empirical analysis. We also include indicators for whether the individual or the firm pays the entire health insurance premium, with cost sharing as the omitted category.

Individuals with coverage from an employer plan (own or spouse) were assigned to the following categories of Employer Provided Retiree Health Insurance (EPRHI) coverage based on their responses to the surveys: (1) covered, (2) not covered, (3) unknown. Table 3 shows that three quarters of the men in the sample have health insurance coverage from their own or spouse's current or former employer, and 69.7 percent of these cases (81 percent of the non-missing cases) have EPRHI coverage. This figure is very similar to coverage reported in other data sources (Fronstin et al. 1994). We also define dichotomous indicators for whether the individual or the employer paid the entire cost of EPRHI coverage; the omitted category is cost sharing. This is important because Continuation Coverage mandated by COBRA requires many firms to provide continued health insurance coverage to workers who leave employment, for up to 18 months after departure. However, the individuals can be charged the full cost of the health insurance. Some individuals in the HRS who indicated that they have EPRHI coverage may in fact not have such coverage but are instead reporting the fact that they are employed in firms that are required to provide continuation of coverage. Continuation coverage mandated by COBRA is likely to have quite different effects than EPRHI on employment decisions because it lasts for only 18 months, so it is important to attempt to distinguish cases with EPRHI from cases with COBRA coverage. The dichotomous indicator for whether the individual pays the entire cost of EPRHI coverage is likely to accurately distinguish COBRA cases from true EPRHI cases since most EPRHI plans involve cost sharing or full payment by the firm (Morrisey, Jensen, and Henderlite, 1990, p. 63). 
Table 3: Sample Statistics

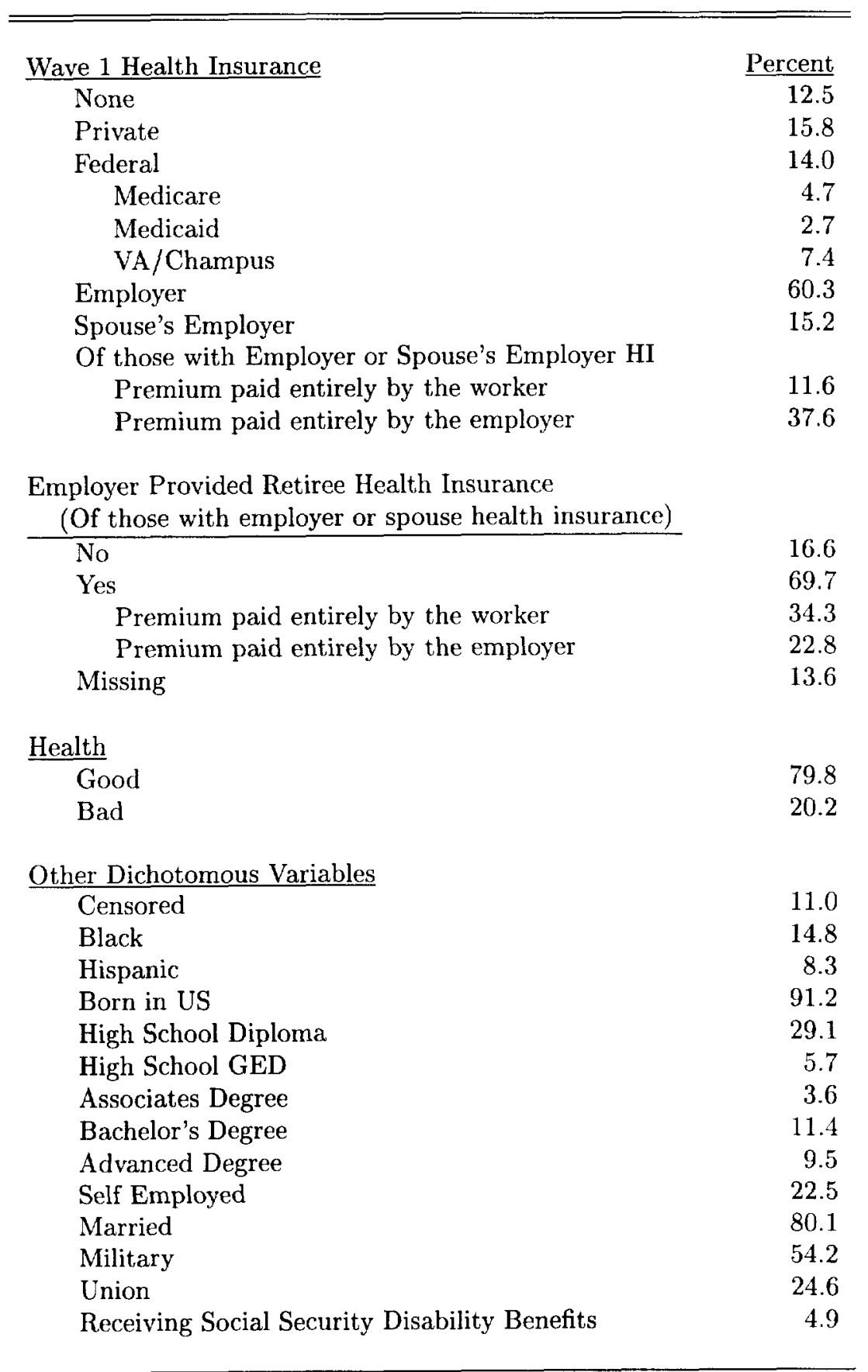


Table 3: Sample Statistics - continued

\begin{tabular}{|c|c|c|}
\hline Other Continuous Variables & Mean & $\underline{\text { Std Dev }}$ \\
\hline Education & $\overline{12.3}$ & $\overline{3.4}$ \\
\hline Age & 55.8 & 3.1 \\
\hline Spouse's age & 52.1 & 26.0 \\
\hline Tenure if employed & 15.3 & 12.1 \\
\hline Duration not employed & 5.8 & 6.8 \\
\hline Wage Rate & 18.1 & 22.0 \\
\hline Current Monthly Social Security Benefit (if $>0$ ) & 620 & 338 \\
\hline Net Worth (1000s) & 249.2 & 559.2 \\
\hline \multicolumn{3}{|l|}{ Family Monthly Income } \\
\hline minus the individual's earnings $(1000 \mathrm{~s})$ & 1.25 & 1.71 \\
\hline Father's Education & 9.0 & 4.0 \\
\hline Father's Educ Missing (\%) & 11.2 & \\
\hline Mother's Education & 9.4 & 3.6 \\
\hline Mother's Educ Missing (\%) & 9.2 & \\
\hline Father is alive (\%) & 17.7 & \\
\hline Father's age & 80.7 & 5.6 \\
\hline Age at which father died & 68.4 & 13.6 \\
\hline Years since father's death & 19.7 & 13.6 \\
\hline Mother is alive (\%) & 43.6 & \\
\hline Mother's age & 79.4 & 5.9 \\
\hline Age at which mother died & 69.0 & 14.3 \\
\hline Years since mother's death & 16.4 & 14.2 \\
\hline Number of siblings & 1.4 & 2.2 \\
\hline \multicolumn{3}{|l|}{ Pension Variables } \\
\hline Defined Benefit Pension (\%) & 55.1 & \\
\hline Eligible for full benefits this year (\%) & 1.7 & \\
\hline Years until eligible for full benefits (if $>0$ ) & 6.6 & 4.4 \\
\hline Years since eligibility for full benefits (if $>0$ ) & 4.3 & 4.2 \\
\hline Eligible for reduced benefits this year (\%) & 4.3 & \\
\hline Years until eligible for reduced benefits (if $>0$ ) & 4.6 & 3.4 \\
\hline Years since eligibility for reduced benefits (if $>0$ ) & 5.0 & 4.1 \\
\hline Employer contribution percent (if $>0$ ) & 13.0 & 21.2 \\
\hline Individual contribution percent (if $>0$ ) & 8.9 & 8.6 \\
\hline Percent Reduction for early benefits (if $>0$ ) & 29.5 & 21.3 \\
\hline Defined Contribution Pension (\%) & 35.0 & \\
\hline Eligible for DC benefits this year (\%) & 1.2 & \\
\hline Years until eligible for $\mathrm{DC}$ benefits (if $>0$ ) & 6.0 & 3.6 \\
\hline Years since eligibility for DC benefits (if $>0$ ) & 4.9 & 4.9 \\
\hline Amount in DC pension account (if $>0)(10,000 \mathrm{~s})$ & 1.6 & 7.1 \\
\hline Eligible for DC benefits this year (\%) & 1.2 & \\
\hline Current monthly pension benefit (if $>0$ ) & 1565.2 & 1335.3 \\
\hline Sample Size & 4,080 & \\
\hline
\end{tabular}

Note: Censored cases include men who were not interviewed in W2 and men who did not supply enough information to determine employment status at $\mathrm{W} 1+1$ or $\mathrm{W} 2$. 
Health Status. The HRS contains numerous detailed measures of health status. We use a dichotomous indicator of self-assessed health status derived by classifying responses of excellent, very good, and good together (denoted "good"), and responses of fair and poor together (denoted "bad").

Income. The behavioral model contains an earnings function $e\left(t, \mathbf{d}_{t}, \mathbf{s}_{t}\right)$ and a nonwage income (benefit) function $b\left(t, \mathbf{d}_{t}, \mathbf{s}_{t}\right)$. In the empirical model, we include as regressors the following elements of $\mathrm{s}_{t}$ : the individual's hourly wage rate if employed; monthly pension and/or Social Security benefits if the individual is currently receiving benefits; an indicator for whether the Social Security benefits, if any, are from the Social Security Disability (SSDI) program ${ }^{14}$ a variety of characteristics of the individual's pension plan that affect the future pension benefit if he is not currently receiving benefits; total nonwage, nonasset income (including the wife's earnings); and the total net worth of the household. The pension plan characteristics include the type of plan (defined benefit or defined contribution; some individuals have both), years until the individual is eligible for benefits, the accumulated amount in the pension account for defined contribution plans, and the percentage reduction in benefits for early retirement. ${ }^{15}$

Other Variables. The other variables included in the employment transition model are age, job tenure, duration of the current spell of nonemployment, education, race, Hispanic ethnicity, marital status, whether the respondent was born in the United States, self-employment status, and union status. A number of other variables are excluded from the employment transition models but are included as identifying instruments in the initial conditions and attrition models. These include dichotomous indicators of educational degrees attained by the respondent; the education of the respondent's mother and father; whether the mother and father are alive and their ages, if alive, or age at death and years since death, if not; the number of siblings; and the wife's age. Descriptive statistics are given in Table 3.

Table 4 provides employment distributions and transition rates from employment at W1 and W1+1 by health status, health insurance coverage, EPRHI coverage, and age, all

\footnotetext{
${ }^{14}$ Variables related to SSDI benefit receipt are included only in the nonemployment to employment transitions because hardly any employed workers receive such benefits.

${ }^{15}$ Other pension characteristics that were included in some versions of the model but eventually dropped were the employer and employee contribution rates, whether benefits can be taken as a lump sum, and whether benefits are adjusted for Social Security, all for defined benefit plans. A considerable amount of additional information about pensions was collected directly from the employers but has not yet been released by the HRS.
} 
measured as of $\mathrm{W} 1 .^{16}$ The employment rate at $\mathrm{W} 1$ is 86.2 percent for men in good health and only 48.0 percent for men in bad health. This large difference illustrates the potential importance of treating initial employment status as endogenous. Men in bad health who are employed at W1 exit the labor force at about twice the rate of men in good health (13.7 versus 6.6 percent). The employment rate at $\mathrm{W} 1$ is highest among men with own-employer health insurance coverage (88.0 percent), private health insurance coverage (85.1 percent), and coverage from the spouse's employer (78.1). Two thirds of men with no health insurance and 64.9 percent of men with VA/CHAMPUS coverage are employed at W1. Men with EPRHI coverage at W1 are 12 percentage points less likely to be employed than men without such coverage (82.9 versus 94.9 percent), and conditional on being employed men with EPRHI are about 35 percent more likely to exit employment by W1+1 than men without EPRHI (7.3 versus 5.4 percent). Interactions between health and EPRHI reveal that men in bad health exhibit large differences in employment at W1 by EPRHI coverage ( 81.8 versus 58.7 percent). While those men in bad health without EPRHI are more likely to be employed at W1, they are 36 percent more likely to exit employment by $W 1+1$ (13.2 versus 9.7 percent) than those with EPRHI coverage. However, among men in bad health who are still employed at $W 1+1$, the exit rate is 71 percent higher for men with EPRHI (14.9 versus 8.7 percent). Table 4 also illustrates the substantially lower employment rate among the older men in the sample and their higher labor force exit rate. Interacting age with EPRHI does not produce a consistent pattern in the employment transitions. The youngest men exit the labor force between W1 and $W 1+1$ at a higher rate when not covered, while the older men exit at a higher rate if covered. Differences in the labor force exit rate between $\mathrm{W} 1+1$ and $\mathrm{W} 2$ by EPRHI coverage are very small at the older ages. ${ }^{17}$ The last two rows of the table show that employment transitions of the self-employed are much less frequent than those of employees. In most of the analysis we pool the self-employed and employees, allowing intercept shifts, but we also

\footnotetext{
${ }^{16}$ As noted above, we use $\mathrm{W} 2$ variables to explain $\mathrm{W} 1+1$ transitions in the empirical model.

${ }^{17}$ Previous studies have not examined how the effect of EPRHI varies with age. Gruber and Madrian (1995, 1996) do not find a consistent pattern of effects of COBRA coverage by age.
} 
Table 4: Cross Tabulations of Employment Transitions by Various Characteristics

\begin{tabular}{|c|c|c|c|c|c|c|c|c|c|}
\hline & \multicolumn{5}{|c|}{ Employed at Wave 1} & \multicolumn{4}{|c|}{ Employed at Wave $1+1$ year } \\
\hline & \multirow[t]{3}{*}{$\underline{\text { Percent }}$} & \multicolumn{4}{|c|}{$\underline{\text { Status at Wave } 1+1 \text { year }}$} & \multirow[t]{3}{*}{$\underline{\text { Percent }}$} & \multicolumn{3}{|c|}{ Status at Wave 2} \\
\hline & & \multirow[t]{2}{*}{ Censored } & \multicolumn{3}{|c|}{ Not Censored } & & & & \\
\hline & & & Same Job & New Job & OLF & & Same Job & New Job & OLF \\
\hline Good Health & 86.2 & 8.1 & 88.8 & 4.7 & 6.6 & 83.7 & 87.9 & 5.2 & 6.9 \\
\hline Bad Health & 48.0 & 12.2 & 79.9 & 6.4 & 13.7 & 44.3 & 83.1 & 4.1 & 12.8 \\
\hline Employer HI & 88.0 & 17.4 & 89.2 & 3.6 & 7.2 & 83.6 & 89.0 & 3.9 & 7.1 \\
\hline Spouse Empl HI & 78.1 & 7.2 & 86.6 & 6.7 & 6.7 & 76.9 & 88.1 & 5.0 & 6.9 \\
\hline No HI & 67.0 & 14.3 & 80.6 & 9.0 & 10.4 & 65.2 & 77.2 & 11.4 & 11.4 \\
\hline Private HI & 85.1 & 7.9 & 91.4 & 4.9 & 4.7 & 83.3 & 88.8 & 4.2 & 6.9 \\
\hline VA/Champus & 64.9 & 9.3 & 82.9 & 5.6 & 13.6 & 61.6 & 86.1 & 3.5 & 10.4 \\
\hline EPRHI & 82.9 & 6.8 & 88.8 & 3.8 & 7.3 & 79.5 & 88.8 & 4.0 & 7.2 \\
\hline No EPRHI & 94.9 & 7.7 & 88.4 & 6.3 & 5.4 & 89.2 & 88.6 & 3.7 & 7.7 \\
\hline Age 51-54 & 85.2 & 8.7 & 88.4 & 5.9 & 5.7 & 83.5 & 88.5 & 5.8 & 5.7 \\
\hline Age $55-58$ & 77.6 & 9.1 & 88.2 & 4.4 & 7.4 & 75.7 & 89.1 & 4.6 & 6.4 \\
\hline Age 59-61 & 69.4 & 9.2 & 85.7 & 3.7 & 10.6 & 64.9 & 82.1 & 4.4 & 13.5 \\
\hline \multicolumn{10}{|l|}{ Good Health } \\
\hline EPRHI & 87.0 & 6.2 & 89.1 & 3.8 & 7.1 & 83.5 & 89.4 & 4.2 & 6.4 \\
\hline No EPRHI & 97.0 & 8.4 & 89.4 & 5.3 & 5.3 & 93.0 & 88.5 & 3.9 & 7.6 \\
\hline \multicolumn{10}{|l|}{ Bad Health } \\
\hline EPRHI & 58.7 & 10.2 & 86.4 & 3.9 & 9.7 & 55.6 & 83.1 & 2.0 & 14.9 \\
\hline No EPRHI & 81.8 & 3.0 & 81.1 & 5.7 & 13.2 & 73.4 & 89.1 & 2.2 & 8.7 \\
\hline \multicolumn{10}{|l|}{ Age 51-54 } \\
\hline EPRHI & 91.6 & 6.6 & 92.2 & 3.9 & 3.9 & 91.1 & 89.7 & 5.0 & 5.2 \\
\hline No EPRHI & 97.5 & 3.0 & 87.6 & 6.4 & 5.9 & 92.2 & 91.4 & 2.9 & 5.7 \\
\hline \multicolumn{10}{|l|}{ Age 55-58 } \\
\hline EPRHI & 81.6 & 7.0 & 87.9 & 3.5 & 8.6 & 78.0 & 91.1 & 3.5 & 5.4 \\
\hline No EPRHI & 94.0 & 11.0 & 90.0 & 5.3 & 4.7 & 92.2 & 89.7 & 4.8 & 5.5 \\
\hline \multicolumn{10}{|l|}{ Age 59-61 } \\
\hline EPRHI & 72.7 & 6.7 & 84.2 & 4.2 & 11.6 & 66.3 & 82.8 & 2.8 & 14.4 \\
\hline No EPRHI & 92.1 & 10.5 & 87.1 & 3.2 & 9.7 & 84.0 & 80.5 & 3.7 & 15.9 \\
\hline Not Self-empl & 100.0 & 7.6 & 86.5 & 5.2 & 8.3 & 91.7 & 87.5 & 5.3 & 7.3 \\
\hline Self-employed & 100.0 & 9.7 & 92.0 & 3.7 & 4.2 & 95.8 & 90.7 & 3.1 & 6.1 \\
\hline
\end{tabular}

Note: Only 5.2 percent of men who report being covered by Medicare are employed at wave 1. The corresponding figure for Medicaid is 8.1 percent. The number of cases is too small to compute reliable transition estimates. 
estimated a specification that excluded the self-employed and found results very similar to those reported below.

\section{Empirical Results}

Table 5 displays the health insurance coefficient estimates from a model without controls for endogeneity and from a model with controls for several sources of endogeneity. We first discuss the results for the model with no endogeneity controls since this specification is similar to those from previous papers. Own employer-provided health insurance is associated with a lower job changing rate, particularly if the individual is in poor health, but the estimates are not statistically significant. Spouse-employer-provided health insurance has little impact on the job changing rate. Most previous studies have found that own or spouse employer health insurance has a negative effect on job switching (Monheit and Cooper, 1994; Gruber and Madrian, 1994; Holtz-Eakin, Penrod, and Rosen, 1996). Job switching is less likely if the firm pays the entire cost of the health insurance premium. EPRHI is associated with a lower rate of job switching for healthy men, offset in part if the man is in poor health or older. None of the EPRHI variables have a statistically significant effect on job switching. There have apparently not been any previous estimates of the effect of EPRHI on job switching in the literature.

Employer health insurance is associated with a lower labor force exit rate, particularly for men in poor health, but the estimates are relatively imprecise. EPRHI is also associated with a lower rate of exit, but the age interaction is positive and precisely estimated. The negative effect of EPRHI on labor force exit diminishes with age and becomes positive by age 57. As indicated in the introduction, previous studies have found a positive effect of EPRHI on labor force exit for older workers (Karoly and Rogowski, 1994; Madrian, 1994). It is interesting to note that the coefficient estimate on the variable indicating that the cost of EPRHI is paid entirely by the worker is -0.537 and is statistically significant at the five percent 


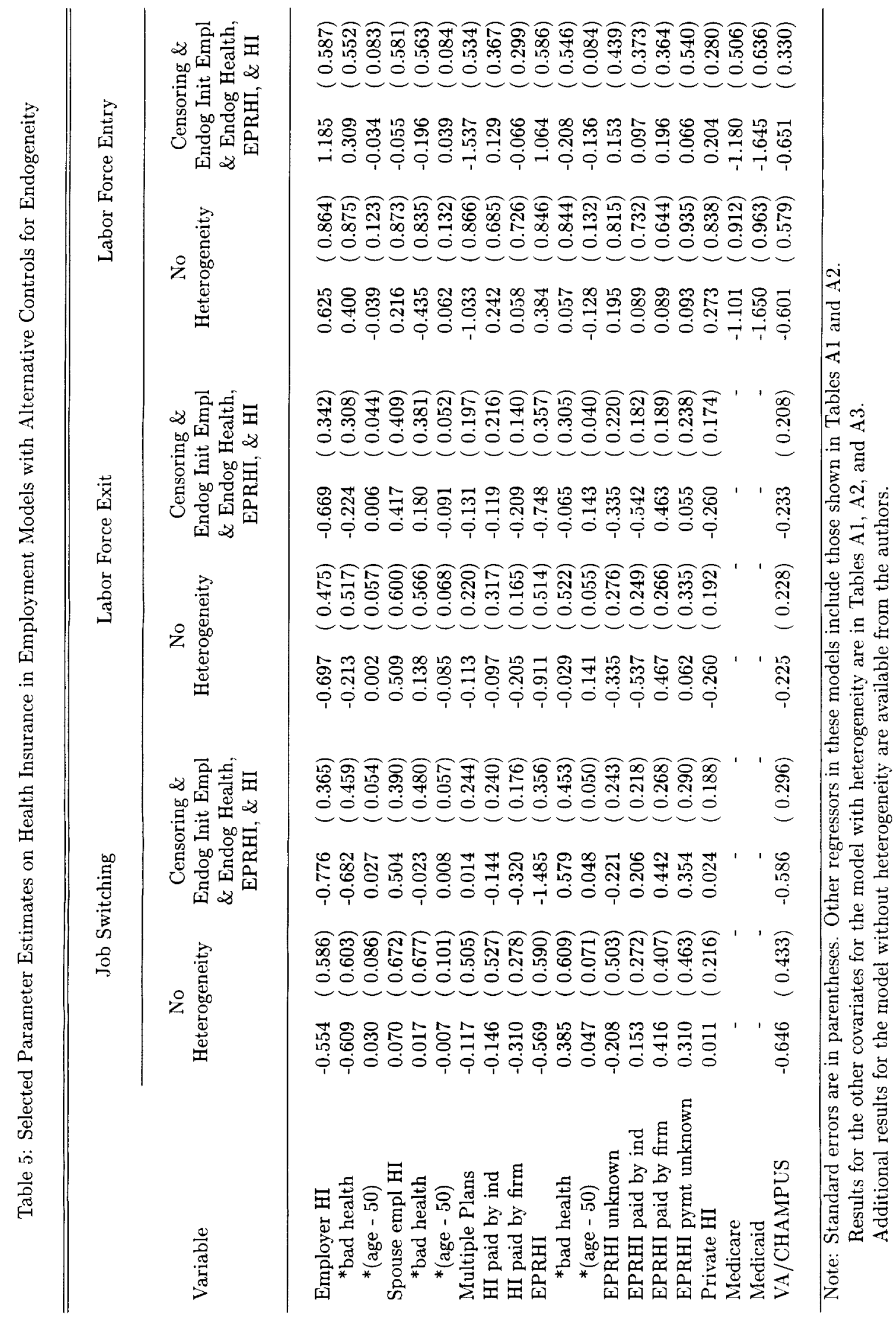


level. As suggested above, workers who report being covered by EPRHI and paying the entire premium may actually not be covered by EPRHI but rather could be mistakenly reporting that they are eligible for continuation coverage under the COBRA mandate. ${ }^{18}$ If this is the case, then we would expect that EPRHI would not have a large positive effect on labor force exit for such individuals, and the results are consistent with this. The negative main effect of EPRHI on labor force exit increases from -0.911 for workers who share the cost of EPRHI with the firm to -1.448 for workers who pay the full cost. Accounting for the age interaction, the effect of EPRHI for the latter group of workers does not turn positive until age 61. The coefficient estimate on the variable indicating that the firm pays the entire EPRHI premium is 0.467 and is statistically significant at the 10 percent level. For this group of workers the EPRHI effect on labor force exit becomes positive by age 54 .

The main effect of EPRHI on the labor force entry rate is positive, though imprecisely estimated, and the health and age interactions are both small and statistically insignificant. Previous studies have not estimated the effect of EPRHI on labor force entry. Medicare, Medicaid, and VA/CHAMPUS coverage all have strong negative effects on labor force entry, but none are precisely estimated.

How robust are these estimates to controls for the endogeneity of attrition, initial conditions, and health insurance? The second column in each panel of Table 5 presents estimates from a model that jointly estimates equations for attrition, employer and spouse health insurance, EPRHI, health status, and initial employment status. ${ }^{19}$ There are some notable differences in the estimated effects of EPRHI with controls for endogeneity. The negative main effect of EPRHI on job switching becomes larger in absolute value and is more precisely estimated. The negative main effect of EPRHI on labor force exit becomes smaller and more

\footnotetext{
${ }^{18}$ We thank Mike Hurd for pointing out this possibility to us.

${ }^{19}$ All of these equations are binary logits. The results are from a model with four points of support in the heterogeneity distribution. This provided a significant improvement in the fit over three points of support, while five points of support provided little further improvement. The model is identified without exclusion restrictions because of the nonlinearity of the discrete factor specification, but as indicated above we have imposed some exclusion restrictions to provide additional identification. A test for overidentification indicated that the hypothesis that the overidentifying variables can be excluded from the employment transition models could not be rejected at the five percent level. We tested whether the identifying variables could be excluded from the auxiliary equations and strongly rejected this hypothesis. We also attempted to estimate a model that allowed job tenure, the wage rate, and other job characteristics to be endogenous, but we were unable to obtain convergence due to the large number of parameters.
} 
precisely estimated while the age interaction remains unchanged. The EPRHI effect on labor force exit turns positive by age 56 in these estimates. The effects of the variables indicating who pays the cost of EPRHI remain unchanged. The positive main effect of EPRHI on labor force entry becomes much larger and is statistically significant at the 10 percent level. The negative interaction with age is also marginally significant and indicates that the effect of EPRHI on labor force entry becomes negative by age 58 .

These findings support the main predictions of the theory. All of the estimated EPRHI effects are in the directions predicted by theory by age 58. At younger ages the EPRHI effects on labor force exit and entry are the opposite of the effects predicted by the theory. This may indicate that jobs offering EPRHI have unobserved desirable features that make them more attractive than jobs without EPRHI. We control for the wage rate and pension plan characteristics, but there may be other important job characteristics that we do not observe. As workers age and the value of nonemployment increases, the EPRHI effects predicted by the theory become apparent in the results. We speculated that if poor health in the present is a good predictor of poor future health, then the EPRHI effects would be stronger for men in poor health. The results do not support this prediction: most of the health-EPRHI interaction coefficients are very small with or without controls for the endogeneity of health, and all are imprecisely estimated. This indicates that EPRHI is equally valuable to men in good and poor health or, possibly, that our measures of good and bad health are not accurate enough to capture greater need for health insurance.

In order to evaluate the quantitative implications of the parameter estimates, we present, simulations in Table 6 and Figure 1 based on the results from the model with heterogeneity in Table $5 .^{20}$ The first two rows of Table 6 show that the model provides a reasonably close fit to the sample transition proportions, though the fit of the model without any heterogeneity is better. On average, EPRHI with cost sharing increases the annual rate of labor force exit from 0.076 to 0.096 , reduces the job switching rate from 0.083 to 0.029 , and increases entry from 0.168 to 0.178 . The effect of EPRHI on labor force exit is much stronger if the firm pays the entire cost of EPRHI: the labor force exit rate rises from 0.076 to 0.138 , an increase

\footnotetext{
${ }^{20}$ The simulations are computed for each individual in the sample, integrating over the estimated heterogeneity distribution, and averaged over the sample.
} 
of six percentage points. The effect on labor force entry is also larger if EPRHI coverage is paid entirely by the firm: the entry rate increases from 0.168 with no EPRHI to 0.201 with EPRHI. The effect of EPRHI on the rate of labor force exit if the individual pays the entire cost is actually negative, though quite small.

Table 6: Employment Simulations

\begin{tabular}{|c|c|c|c|c|c|}
\hline & \multicolumn{3}{|c|}{ Transitions from Employment } & \multicolumn{2}{|c|}{ Transitions from OLF } \\
\hline & Same Job & New Job & OLF & OLF & Empl \\
\hline Actual Distribution & 0.8754 & 0.0497 & 0.0749 & 0.8944 & 0.1056 \\
\hline Predicted Distribution & 0.8431 & 0.0732 & 0.0836 & 0.8914 & 0.1086 \\
\hline EPRHI: no & 0.8410 & 0.0827 & 0.0764 & 0.8319 & 0.1681 \\
\hline EPRHI: yes - cost sharing & 0.8743 & 0.0294 & 0.0963 & 0.8221 & 0.1779 \\
\hline EPRHI: yes - paid by firm & 0.8204 & 0.0420 & 0.1376 & 0.7991 & 0.2009 \\
\hline EPRHI: yes - paid by ind & 0.9029 & 0.0371 & 0.0599 & 0.8109 & 0.1891 \\
\hline
\end{tabular}

Figure 1 shows how labor force exit and entry, respectively, vary with age and EPRHI. The age effect on exit for men with health insurance from their own employer but no EPRHI is relatively small: 0.068 to 0.085 from ages 51 to 61 . The age gradient is much larger for men with EPRHI: 0.041 to 0.172 . The age gradient for labor force entry is also strongly affected by EPRHI : 0.260 to 0.126 for men without EPRHI versus 0.403 to 0.086 for men with EPRHI. These large differences clearly indicate a major role of EPRHI that is not due to unobserved heterogeneity associated with attrition, health insurance and EPRHI coverage, or initial employment and health status.

How do the estimated effects of EPRHI on employment transitions of older men presented here compare to previous estimates from other sources? Karoly and Rogowski (1994) did not have data on EPRHI in their SIPP sample of men aged 55-62 and were forced to impute it on the basis of firm size, industry, and region. Their estimates indicate that EPRHI increases the probability of retiring within a two and one half year period by eight percentage points from a base of 17 percent. As Madrian (1994) notes, this is likely to be an overestimate because other 

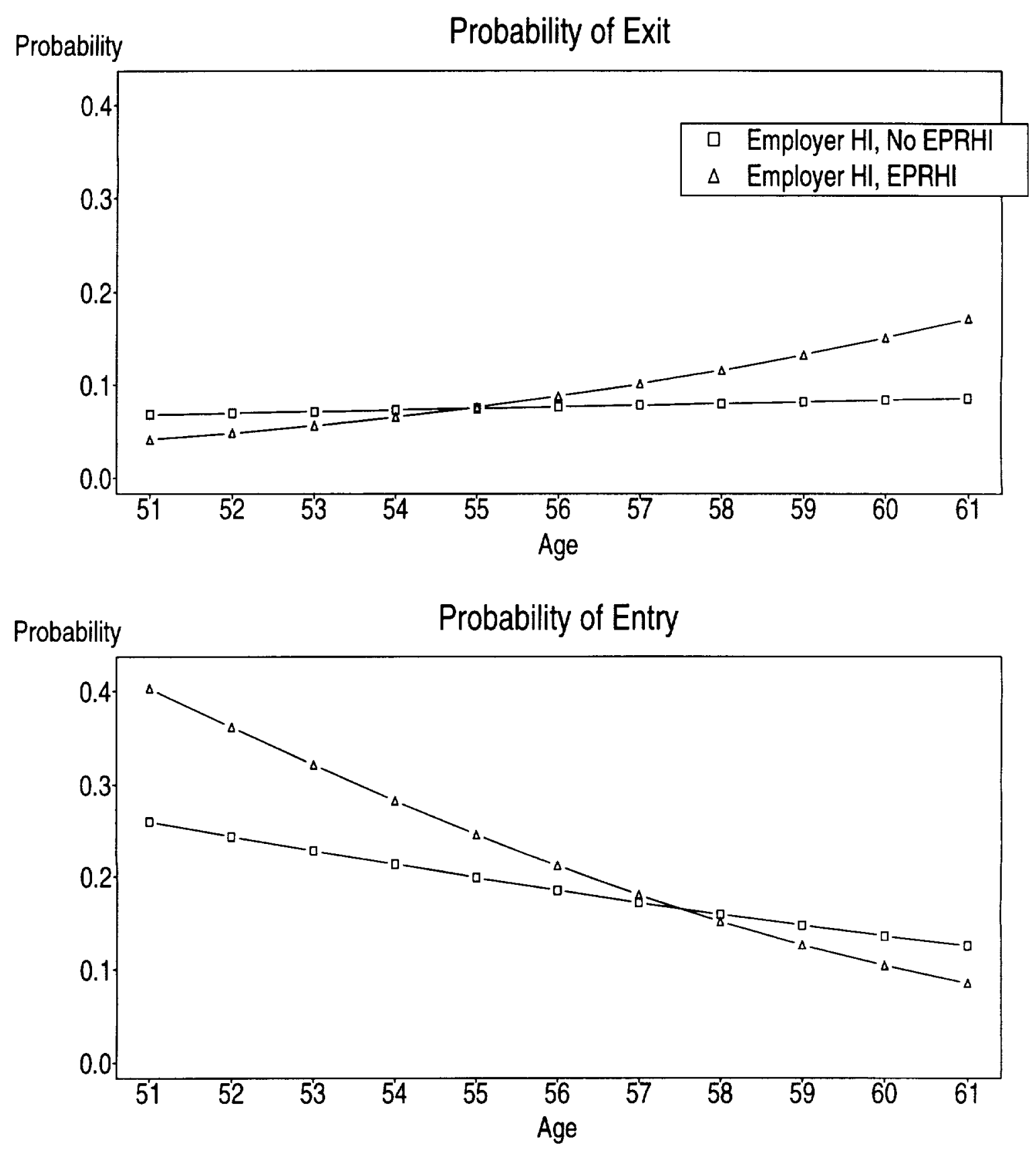

Figure 1: Labor Force Exit and Entry Rates by Age and Health Insurance 
factors associated with firm size and industry that are unmeasured by Karoly and Rogowski (such as pensions and working conditions) are likely to have a positive impact on retirement as well. Nevertheless, this estimate is smaller than ours: at age 58, which is the average age in the sample used by Karoly and Rogowski we find a 3.8 percentage point effect on exit from employment during a one year period with cost sharing, and an eight percentage point effect if the firm pays the entire cost. Madrian (1994) uses samples of men aged 55-84 who had already retired as of the survey date in two SIPP samples and in the National Medical Expenditure Survey (NMES) to estimate the effect of EPRHI on the age at retirement. Her results show that EPRHI reduces the age at retirement by 1.2 years in the NMES data and by 0.4 to 0.7 years in the SIPP data. She notes the obvious potential for biases due to sample truncation on being retired and alive at the survey date, and suggests that these biases are likely to be toward zero. Similarly ignoring the risk of labor market reentry and extrapolating the linear age effects beyond age 62, our estimates imply that an average man who was employed at age 51 with employer-health insurance would retire two years earlier with EPRHI than without it. When we account for labor force reentry, this figure increases to 8.7 years. ${ }^{21}$

Gruber and Madrian (1995) estimated that the annual hazard rate for retirement of men aged 55-64 was 1.7 percentage points higher as a result of the availability of COBRA continuation coverage mandates. Measured in terms of the months of continuation coverage provided, their estimates imply that a year of continuation coverage raises the retirement hazard rate by 2.2 percentage points. Gruber and Madrian (1996) estimate that one year of continuation coverage availability increases the stock of retirees among men aged 55-64 by 1.1 percentage points on average, which represents a 5.4 percent increase in the probability of being retired. Continuation coverage mandates provide a maximum of 18 months of coverage after leaving an employer, so it is not clear whether their estimates can bo meaningfully compared to ours. Our estimates of the effect of EPRHI on labor force exit are larger than Gruber and Madrian's (1995) estimates of the effect of continuation coverage when evaluated at the average age in their sample. Furthermore, our estimates imply that in a sample of men

\footnotetext{
${ }^{21}$ Both calculations are based on simulations of 10,000 individuals. The difference between the no-reentry and reentry figures is attributed to extrapolation of entry and exit probabilities beyond the oldest observed age. That is, probabilities of reentering with EPRHI are essentially zero at ages above 64 (as implied by the steep gradient in Figure 1) and the differences in exit rates with and without EPRHI increase as individuals age beyond 55 .
} 
who are all employed at age 51, those who have EPRHI will have a nonemployment rate of 0.66 by age 62 , while those who do not have EPRHI will have a nonemployment rate of 0.58 by age 62 . This is a 12 percent difference, substantially larger than the average effect reported by Gruber and Madrian (1996), and also larger than all but one of the age-specific effects they report. Finally, Rust and Phelan (forthcoming) estimate that men with health insurance that is not tied to employment have a two-year labor force exit rate that is nine percentage points higher at ages 60-61 than the rate for men with employer health insurance in their RHS sample. This does not correspond precisely to the EPRHI/non-EPRHI distinction, but is a reasonable approximation given the available data in the RHS. Our estimates imply an effect of EPRHI on the one-year labor force exit rate of almost nine percentage points at age 61 (see Figure 1).

What accounts for the larger effects of EPRHI on the labor force exit rate of men that we find compared to those found in earlier studies? Three possible explanations are that our data measure EPRHI more accurately, we control for the possible endogeneity of EPRHI and other key variables, and we use data from the 1990's rather than earlier periods. We cannot determine the importance of the last factor, but we can shed some light on the possible role of measurement and endogeneity. Most of the earlier studies did not have access to accurate data on EPRHI coverage. Karoly and Rogowski (1994) used an employer survey to estimate an equation to explain EPRHI as a function of industry, firm size, and region, and then used the coefficient estimates to impute EPRHI to the workers in their SIPP sample. We replicated their approach by estimating an equation with a specification identical to theirs using the HRS data. We reestimated our model of employment transitions using an imputed measure of EPRHI constructed from the estimated EPRHI equation (setting EPRHI to zero if the individual did not have employer-provided health insurance, and omitting the auxiliary EPRHI equation from the model). Using the imputed measure of EPRHI reduces the magnitude of most of the estimated EPRHI effects compared to using a reported measure of EPRHI. For example, at age 56 the negative effect of EPRHI on job switching is 24 percent smaller, the estimated effect of EPRHI on labor force exit is negative rather than positive, and the estimated effect of EPRHI on labor force entry is about the same compared to the results 
using reported EPRHI. These findings suggest that the relatively accurate measure of EPRHI coverage available in the HRS may help account for the larger effects that we find.

The coefficient estimates in Table 5 indicate that controlling for the endogeneity of EPRHI and other variables causes a large increase in the negative effect of EPRHI on job switching, a reduction of two years in the age by which the EPRHI effect on labor force exit becomes positive, but an increase of about five years in the age at which the effect of EPRHI on labor force entry becomes negative. Previous studies have examined the effect of EPRHI on labor force exit, and our results suggest that treating EPRHI as exogenous may have led those studies to underestimate the impact of EPRHI on labor force exit.

\section{Conclusion}

Our results lead us to three conclusions. First, retiree health insurance appears to be an important factor in the employment transition decisions of older men. Differences in the employment exit rate by EPRHI average 0.02 per year and are as high as 0.11 per year at age 61. Differences in the employment entry rate by EPRHI average 0.03 and reach 0.09 at age 61. These effects are larger than those found in previous studies. This is likely due in part to better data that provide both more accurate EPRHI measures and a longitudinal design. It is also possible that the impact of EPRHI has increased in the 1990's compared to the 1970's and 1980's when the data used in previous studies were collected. The fact that we are able to control for many other job characteristics that could be correlated with EPRHI coverage makes it unlikely that the estimated effects of the EPRHI variables are biased as a result of omitted job characteristics.

Second, controlling for unobserved heterogeneity has a substantial impact on the estimates. Simulations based on the no-heterogeneity results from Table 5 imply that EPRHI increases the average labor force exit rate by 0.0037 compared to the 0.02 increase implied by the results that incorporate endogeneity. The no-heterogeneity results imply that EPRHI causes a decrease in the job switching rate of 0.012 compared to the 0.053 decrease implied by the preferred model. On the other hand, the reduction in the labor force entry rate caused by EPRHI is much larger in the no-heterogeneity case: 0.052 versus 0.010 . Previous studies have 
not accounted for unobserved heterogeneity, and this may help explain why our estimates of the effect of EPRHI on labor force exit is larger than in past studies.

Finally, we believe that our estimates clearly indicate the potential value of estimating the structural parameters of a model of employment and medical care decisions. EPRHI effects are clearly important, and health insurance reform could therefore have a major impact on the labor force behavior of older individuals. This impact cannot be quantified without believable estimates of fundamental behavioral parameters. Among the many important benefits of the HRS, the future availability of detailed health insurance and pension plan characteristics along with Social Security earnings histories will make it possible to obtain such estimates. 


\section{Appendix}

Recall from Section 2, equation 7 that the probability of making a transition from employment state $k$ to $j$ is given by

$$
\begin{aligned}
\mathrm{P}\left(V_{k j t}>V_{k j^{\prime} t}, \forall j^{\prime} \neq j\right) & =\frac{\exp \left(\mathbf{X}_{t-1} \gamma_{k j}+\rho_{k j} \mu\right)}{\sum_{j^{\prime}=1}^{J_{k}} \exp \left(\mathbf{X}_{t-1} \gamma_{k j^{\prime}}+\rho_{k j^{\prime}} \mu\right)} \\
& =\mathrm{p}\left(d_{t=1}^{j} 1 \mid d_{t-1}^{k}=1, \mu\right) .
\end{aligned}
$$

Let $J_{k}$ indicate the number of employment alternatives available to an individual who chose employment state $k$ in the previous period. Let $\Theta$ denote the vector of parameters in the model, including the points of support of the distribution of $\mu$ and their factor loadings. The probability of health insurance coverage through one's employer or spouse's employer, EPRHI, and health status at $t$ is denoted by $I_{h}\left(\mathbf{A}_{t-1}, \eta_{h}, \rho_{2 h} \mu\right)$ where $h$ indicates the particular health or health insurance equation, $A_{t-1}$ is a vector of time-varying and constant explanatory variables, $\eta_{h}$ is a parameter vector, and $\rho_{2 h}$ is a factor loading. The contribution of individual $n$ to the likelihood function, conditional on $\mu$, is

$$
\mathcal{L}_{n}(\Theta \mid \mu)=\prod_{t=1}^{T}\left[\prod_{j=1}^{J_{k}} \mathrm{p}\left(d_{t}^{j}=1 \mid d_{t-1}^{k}=1, \mu\right)^{d_{t}^{j}} \prod_{h=1}^{H} I_{h}\left(\mathbf{A}_{t-1}, \eta_{h}, \rho_{2 h} \mu\right)\right]
$$

Unconditional on the permanent error component $\mu$, the likelihood contribution of individual $n$ is

$$
\mathcal{L}_{n}(\Theta, \theta)=\sum_{m=1}^{M} \theta_{m} \mathcal{L}_{n}\left(\Theta \mid \mu_{m}\right)
$$

where $\theta$ is the vector of probabilities of the $M$ points of support of the heterogeneity distribution. Let $I_{c}\left(\mathbf{B}, \eta_{c}, \rho_{3 c} \mu\right)$ represent the probability of observing a given value of the $c^{\prime}$ th initial condition as of the initial survey (employment status, etc.), where $\mathbf{B}$ is a vector of non-time-varying explanatory variables, $\eta_{c}$ is a parameter vector, and $\rho_{3 c}$ is a factor loading. The likelihood contribution of individual $n$ in this case is

$$
\mathcal{L}_{n}(\Theta, \eta, \theta)=\sum_{m=1}^{M} \theta_{m}\left\{\mathcal{L}_{n}(\Theta \mid \mu) \prod_{c=1}^{C} I_{c}\left(\mathbf{B}, \eta_{c}, \rho_{3 c} \mu_{m}\right)\right\}
$$

where $C$ is the number of initial conditions. Data on the initial conditions along with data on B identify the $\eta$ 's and $\rho$ 's. Finally, the likelihood function for a sample of size $N$ is

$$
\mathcal{L}(\Theta, \eta, \theta)=\prod_{n=1}^{N} \mathcal{L}_{n}(\Theta, \eta, \theta)
$$


Table A1: Logit Results for Employment Transitions:

Additional Results from the Model with Heterogeneity

\begin{tabular}{|c|c|c|c|c|c|c|}
\hline \multirow[b]{3}{*}{ Defined Benefit } & \multicolumn{4}{|c|}{$\begin{array}{c}\text { Transitions } \\
\text { from Employment }\end{array}$} & \multirow{2}{*}{\multicolumn{2}{|c|}{$\begin{array}{c}\begin{array}{c}\text { Transitions } \\
\text { from Non empl }\end{array} \\
\text { To New Job }\end{array}$}} \\
\hline & \multicolumn{2}{|c|}{ To New Job } & \multicolumn{2}{|c|}{ To Non Empl } & & \\
\hline & -0.118 & $(0.158)$ & 0.075 & $(0.146)$ & -0.144 & $(0.250)$ \\
\hline Eligible now & 0.611 & $(0.368)$ & 0.507 & $(0.238)$ & 0.745 & $(0.442)$ \\
\hline Years until eligible & -0.032 & $(0.037)$ & -0.111 & $(0.036)$ & 0.132 & $(0.074)$ \\
\hline Years since eligibility & 0.038 & $(0.053)$ & 0.032 & $(0.026)$ & 0.038 & $(0.042)$ \\
\hline Monthly Benefit & 0.079 & $(0.074)$ & 0.055 & $(0.061)$ & -0.190 & $(0.153)$ \\
\hline Benefit Missing & -0.060 & $(0.187)$ & 0.262 & $(0.141)$ & -0.519 & $(0.275)$ \\
\hline Percent reduction for early retirement & -0.015 & $(0.009)$ & -0.017 & $(0.007)$ & -0.029 & $(0.050)$ \\
\hline Reduction for early retirement missing & -0.424 & $(0.240)$ & 0.071 & $(0.168)$ & -0.804 & $(0.465)$ \\
\hline Defined Contribution & -0.066 & $(0.160)$ & -0.351 & $(0.132)$ & 0.057 & $(0.253)$ \\
\hline Eligible now & 0.296 & $(0.495)$ & -0.339 & $(0.488)$ & - & - \\
\hline Years until eligible & -0.010 & $(0.032)$ & -0.051 & $(0.037)$ & 0.125 & $(0.070)$ \\
\hline Years since eligibility & -0.039 & $(0.095)$ & 0.013 & $(0.057)$ & -0.017 & $(0.121)$ \\
\hline Amount in account & -0.009 & $(0.016)$ & -0.018 & $(0.011)$ & 0.036 & $(0.025)$ \\
\hline Receiving SS Disability & - & - & - & - & -1.749 & $(0.606)$ \\
\hline Monthly benefit & - & - & - & - & 0.166 & $(0.444)$ \\
\hline Net Worth & -0.068 & $(0.030)$ & 0.009 & $(0.012)$ & -0.134 & $(0.043)$ \\
\hline Wage Rate & -0.011 & $(0.007)$ & 0.008 & $(0.003)$ & - & - \\
\hline Non-earned Income & 0.032 & $(0.038)$ & 0.050 & $(0.029)$ & -0.013 & $(0.063)$ \\
\hline Age & -0.071 & $(0.037)$ & 0.017 & $(0.033)$ & -0.071 & $(0.042)$ \\
\hline Bad Health & 0.185 & $(0.259)$ & 1.079 & $(0.217)$ & -1.450 & $(0.319)$ \\
\hline Hispanic & -0.091 & $(0.254)$ & 0.019 & $(0.237)$ & -0.627 & $(0.370)$ \\
\hline Black & -0.658 & $(0.233)$ & -0.026 & $(0.161)$ & -0.035 & $(0.260)$ \\
\hline Born in US & 0.434 & $(0.243)$ & 0.658 & $(0.239)$ & -0.994 & $(0.335)$ \\
\hline Married & -0.430 & $(0.163)$ & -0.561 & $(0.139)$ & 0.422 & $(0.245)$ \\
\hline Military & 0.015 & $(0.136)$ & 0.224 & $(0.120)$ & 0.294 & $(0.213)$ \\
\hline Education & 0.018 & $(0.024)$ & 0.039 & $(0.020)$ & 0.060 & $(0.032)$ \\
\hline Tenure & -0.057 & $(0.008)$ & -0.002 & $(0.005)$ & -0.096 & $(0.030)$ \\
\hline Self employed & -0.475 & $(0.185)$ & -2.302 & $(0.234)$ & - & - \\
\hline Union & -0.084 & $(0.196)$ & -0.761 & $(0.161)$ & - & - \\
\hline Intercept & -0.360 & $(0.422)$ & -2.606 & $(0.414)$ & -1.099 & $(0.571)$ \\
\hline Rho & 1.000 & - & -0.191 & $(0.177)$ & -1.085 & $(0.335)$ \\
\hline Log likelihood & $-19,301.6$ & & & & & \\
\hline
\end{tabular}

Note: Standard errors are in parentheses. Net worth is in units of hundreds of thousands of dollars, other income and pension accumulation are in units of tens of thousands of dollars, and Social Security and pension benefits are in units of thousands of dollars per month. 


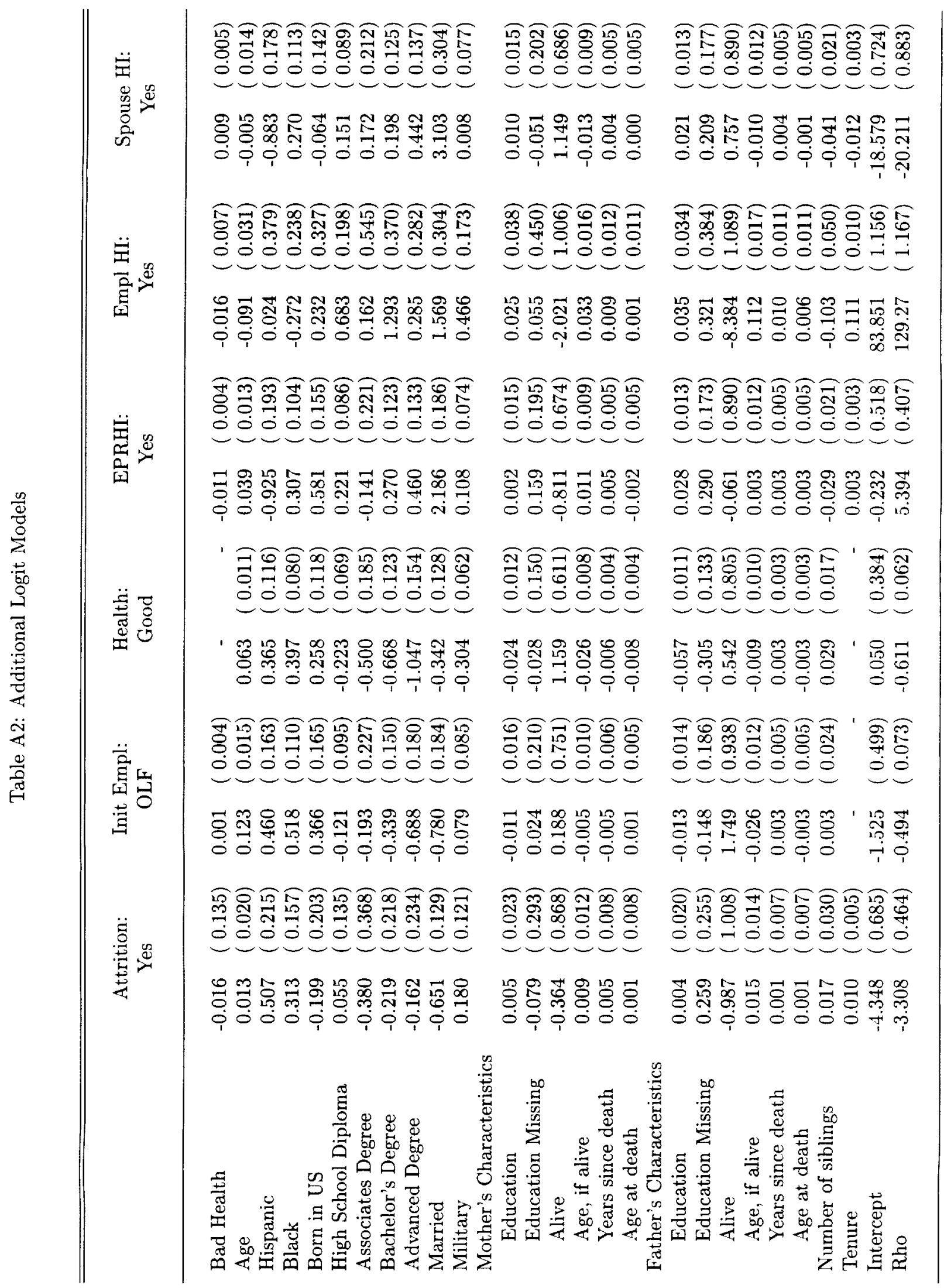


Table A3: Unobserved Heterogeneity Results

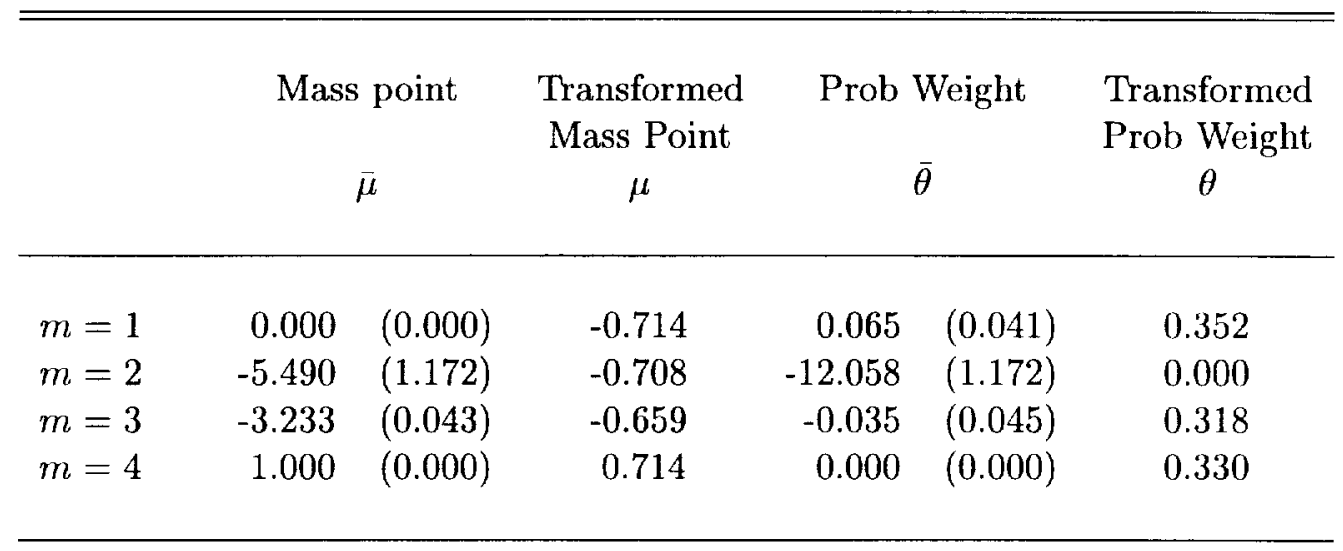

The transformed mass points:

$$
\begin{aligned}
& \mu_{1}=\left(\bar{\mu}_{1}-0.5\right) \times s \\
& \mu_{2}=\left(\frac{1}{1+\exp \bar{\mu}_{2}}-0.5\right) \times s \\
& \mu_{3}=\left(\frac{1}{1+\exp \bar{\mu}_{3}}-0.5\right) \times s \\
& \mu_{4}=\left(\bar{\mu}_{4}-0.5\right) \times s
\end{aligned}
$$

where $s$ is estimated to be 1.427 with standard error 0.029 .

The transformed probability weights:

$$
\begin{aligned}
& \theta_{m}=\frac{\exp \bar{\theta}_{m}}{1+\sum_{m^{\prime}=1}^{M-1}\left(\exp \bar{\theta}_{m^{\prime}}\right)}, \quad m=1, \ldots, M-1 \\
& \theta_{M}=\frac{1}{1+\sum_{m^{\prime}=1}^{M-1}\left(\exp \bar{\theta}_{m^{\prime}}\right)}, \quad m=M
\end{aligned}
$$




\section{References}

Blau, D. (1994). "Labor Force Dynamics of Older Men," Econometrica 62 (1): 117-156.

Blau, D. and D. Gilleskie (1996). "Health Insurance and Retirement in the 1990's: A Dynamic Structural Analysis," unpublished manuscript, University of North Carolina, Chapel Hill.

Burkhauser, R. and J. Quinn (1994). "Changing Policy Signals," in M. W. Riley, R. L. Kahn, and A. Foner (eds.) Age and Structural Lag, New York: Wiley.

Burtless, G. and R. Moffitt (1985). "The Joint Choice of Retirement Age and Postretirement Hours of Work," Journal of Labor Economics 3: 209-236.

Cameron, A.C., P.K. Trivedi, F. Milne, and J. Piggott (1988). "A Microeconometric Model of the Demand for Health Care and Health Insurance in Australia," Review of Economic Studies 55: 85-106.

Fronstin, P., S.C. Snider, W.S. Custer, and D.S. Salisbury (1994). "The Cost of Providing Health Care Benefits to Early Retirees," Health Affairs 13 (Spring): 246-254.

Gilleskie, D. (1997). "A Dynamic Stochastic Model of Medical Care Use and Work Absence," manuscript, University of North Carolina at Chapel Hill.

Gruber, J. and B.C. Madrian (1994). "Health Insurance and Job Mobility: The Effects of Public Policy on Job Lock," Industrial and Labor Relations Review 48 (1): 86-102.

Gruber, J. and B.C. Madrian (1995). "Health Insurance Availability and the Retirement Decision," American Economic Review 85: 938-48.

Gruber, J. and B.C. Madrian (1996). "Health Insurance and Early Retirement: Evidence from the Availability of Continuation Coverage," in David Wise (ed.) Advances in the Economics of Aging, University of Chicago Press.

Gustman, A. and T. Steinmeier (1994). "Employer-Provided Health Insurance and Retirement Behavior," Industrial and Labor Relations Review 48 (October): 124-140.

Heckman, J.J. (1981). "The Incidental Parameters Problem and the Problem of Initial Conditions in Estimating a Discrete Time-Discrete Data Stochastic Process," in C. Manski and D. McFadden (eds.) Structural Analysis of Discrete Data with Econometric Applications, Cambridge: The MIT Press.

Heckman, J. and B. Singer (1984). "A Method for Minimizing the Impact of Distributional Assumptions in Econometric Models for Duration Data," Econometrica 52: 271-320.

Holtz-Eakin, D., J.R. Penrod, and H.S. Rosen(1996). "Health Insurance and the Supply of Entrepreneurs," Journal of Public Economics 62: 209-235.

Hurd, M. (1990). "Research on the Elderly:Economic Status, Retirement, and Consumption and Saving," Journal of Economic Literature 28: 565-637. 
Jensen, G.A. and M.A. Morrisey (1992). "Employer-Sponsored Postretirement Health Benefits: Not Your Mother's Medigap Plan," The Gerontologist 32: 693-703.

Kahn, J. (1988). "Social Security, Liquidity, and Early Retirement," Journal of Public Economics 35: 97-117.

Karoly, L.A. and J.A. Rogowski (1994). "The Effect of Access to Post-Retirement Health Insurance on the Decision to Retire Early," Industrial and Labor Relations Review 48 (October): $103-123$.

Krueger, A. and J-S. Pischke (1992). "The Effect of Social Security on Labor Supply: A Cohort Analysis of the Notch Generation," Journal of Labor Economics 10: 412-437.

Loprest, P. And S. Zedlewski (1995). "Health Insurance Coverage Transitions of Older Americans: Early Results Based on the 1992-1994 Health and Retirement Study," manuscript, The Urban Institute.

Lumsdaine, R.L., J.H. Stock, and D.A. Wise (1994). "Pension Plan Provisions and Retirement: Men and Women, Medicare, and Models," in D.A. Wise (ed.) Studies in the Economics of Aging, Chicago: University of Chicago Press.

Lumsdaine, R.L., J.H. Stock, and D.A. Wise (1996). "Why are Retirement Rates so High at Age 65?" in D.A. Wise (ed.) Advances in the Economics of Aging, Chicago: University of Chicago Press.

Madrian, B.C. (1994). "The Effect of Health Insurance on Retirement," Brookings Papers on Economic Activity, 181-232.

Moffitt, Robert A. (1987). "Life-Cycle Labor Supply and Social Security: A Time Series Analysis," in Gary Burtless (ed.), Work, Health and Income Among the Elderly, Washington, DC: The Brookings Institution.

Monheit, A.C. and P.F. Cooper (1994). "Health Insurance and Job Mobility: Theory and Evidence," Industrial and Labor Relations Review 48 (October): 68-85.

Morrisey, M.A. (1993). "Retiree Health Benefits," Annual Review of Public Health 14: 271292.

Morrisey, M.A., G.A. Jensen, and S.E. Henderlite (1990). "Employer-Sponsored Health Insurance for Retired Americans," Health Affairs 9 (Spring): 59-73.

Mroz, T. And D. Guilkey (1992). "Discrete Factor Approximations for Use in Simultaneous Equation Models with Both Continuous and Discrete Endogenous Variables," manuscript, University of North Carolina at Chapel Hill.

Peracchi, F. and F. Welch (1994). "Labor Force Transitions of Older Workers," Journal of Labor Economics 12 (2): 210-242.

Ruhm, C. (1990). "Bridge Jobs and Partial Retirement," Journal of Labor Economics 8: 482-501. 
Rust, J. and C. Phelan (forthcoming). "How Social Security and Medicare Affect Retirement Behavior in a World of Incomplete Markets," Econometrica.

Shea, D.G. and R.P. Stewart (1994). "Ability to Pay for Retiree Health Benefits," Inquiry 31 (Summer): 206-214.

Stewart, J. (1994). "Do Older Workers Respond to Changes in Social Security? A Times Series Look at the Effects of Anticipated and Unanticipated Changes in the Level of Benefits," manuscript, Bureau of Labor Statistics, Washington, DC.

Wilcox-Gök, V. and J. Rubin (1994). "Health Insurance Coverage Among the Elderly," Social Science and Medicine 38 (11): 1521-1529. 